\title{
Efficacy and safety of antitumor agents plus radiotherapy compared with radiotherapy alone for brain metastases from lung cancer
}

\author{
HENG LIN ${ }^{1,2 *}$, SHUIMEI LUO ${ }^{2 *}$, LINA LI $^{2}$, SIJING ZHOU ${ }^{2}$, \\ RUIFEN SHEN ${ }^{2}$, HAITAO YANG ${ }^{2}$, YUPENG WU ${ }^{2}$ and XIANHE XIE ${ }^{2}$ \\ ${ }^{1}$ Department of Oncology, Fuzhou Pulmonary Hospital, Fuzhou, Fujian 350008; ${ }^{2}$ Department of Chemotherapy, \\ The First Affiliated Hospital of Fujian Medical University, Fuzhou, Fujian 350005, P.R. China
}

Received April 21, 2016; Accepted July 27, 2016

DOI: $10.3892 / \mathrm{mco} .2017 .1152$

\begin{abstract}
The present study aimed to investigate the efficacy and safety of different therapeutic regimens for brain metastases (BMs) from lung cancer (LC). A total of 13 controlled trials (1,783 cases) involving chemotherapy, tyrosine kinase inhibitors or endostatin plus radiotherapy (combination group) vs. radiotherapy alone group were identified from PubMed. Compared with the radiotherapy alone group, the combination group resulted in a significant benefit for objective response rate (ORR) [risk ratio (RR), 1.38; 95\% confidence interval (CI), 1.19-1.60; $\mathrm{P}<0.0001]$, notably prolonged the time to central nervous system progression [CNS-TTP; hazard ratio (HR), 0.71; 95\% CI, 0.57-0.90; $\mathrm{P}=0.004]$ and progression-free survival (PFS; HR, 0.60; 95\% CI, 0.44-0.83; $\mathrm{P}=0.002$ ); however, failed in prolonging the overall survival (OS; HR, 0.80; 95\% CI, 0.61-1.05; $\mathrm{P}=0.11$ ) with a higher overall severe adverse events (AEs, Grade $\geq 3$; RR, 2.57; 95\% CI, 1.24-5.35; $\mathrm{P}=0.01$ ). Notably, subgroup analysis demonstrated that targeted therapy plus radiotherapy possessed a superior OS compared with radiotherapy alone (HR, $0.58 ; 95 \% \mathrm{CI}, 0.37-0.90 ; \mathrm{P}=0.01$ ) with mild non-hematological toxicity and without severe hematotoxicity. The present study demonstrated that targeted agents plus radiotherapy possessed desirable effects with mild adverse events. Secondary to best, chemoradiotherapy is an alternative option for patients without suitable molecular targets.
\end{abstract}

Correspondence to: Professor Xianhe Xie, Department of Chemotherapy, The First Affiliated Hospital of Fujian Medical University, 20 Chazhong Road, Fuzhou, Fujian 350005, P.R. China E-mail: xiexianhe@yahoo.com

*Contributed equally

Key words: brain metastases, lung cancer, antitumor agents, targeted agents, chemotherapy, radiotherapy, meta-analysis

\section{Introduction}

Brain metastases (BMs), the most common neurological complication, develop in $20-40 \%$ of patients with cancer (1). In $40-50 \%$ of these patients, the dominant primary tumor was lung cancer (LC) (2). Patients with LC who presented BMs at their initial primary tumor diagnosis had a poor prognosis in untreated patients $(3,4)$. Surgery, whole brain radiation therapy (WBRT) and stereotactic radiosurgery (SRS) were frequently applied to the treatment of BMs. A limited number (predominantly 1-3 and in certain cases $>3$ ) of BMs can be effectively intervened by surgical resection or SRS $(5,6)$. However, a considerable proportion of patients, being unsuitable for surgery or SRS, were controlled using a palliative approach, including WBRT, to improve neurological symptoms and local lesions. Unfortunately, radiotherapy can only prolong the median survival time to 6 months for LC patients with BMs (7). Therefore, establishing a multimodality therapy, including targeted agents or chemotherapy plus radiotherapy, is urgently required to maximize the therapeutic effect. Accordingly, certain relevant trials $(8,9)$ combining antitumor agents with radiotherapy have been performed in recent decades. Some of these treatments demonstrated favorable efficacy and safety of antitumor agents plus radiotherapy in dealing with BMs $(3,10-17)$, while other trials failed to confirm this (18-21). The role of antitumor agents plus radiotherapy for managing BMs remains controversial. Therefore, the present study performed a meta-analysis to investigate the efficacy and safety of antitumor agents plus radiotherapy compared with radiotherapy alone for BMs from lung cancer, to optimize the therapeutic strategy.

\section{Materials and methods}

Data sources and search. A thorough search in PubMed was performed without language restriction from inception until October 2015 using the following keywords and Mesh terms: ['anti-tumor agents' (all fields) OR 'anti-cancer drugs' (all fields)] AND ['EGFR tyrosine kinase inhibitors' (all fields) OR 'epidermal growth factor receptor' (all fields) OR 'targeted agents' (all fields)] AND ['chemotherapy' (all fields) AND 
'irradiation' (all fields) OR 'radiation therapy' (all fields) OR 'radiotherapy' (all fields) OR 'radiotherapeutics' (all fields)] AND ['lung cancer' (Mesh) OR 'lung neoplasms' (Mesh) OR 'lung carcinoma' (Mesh)] AND ['brain metastases' (Mesh) OR 'intracranial metastases' (Mesh) OR 'intracranial metastatic tumor' (Mesh) OR 'brain neoplasms' (Mesh)']. All reviews, and preclinical and animal trials were excluded.

Study selection. Eligible trials were those that met the following criteria: i) Randomized controlled trials (RCTs) or clinical controlled trails with voluntarily enrolled patients; ii) Patients suffered from histologically or cytologically confirmed lung cancer and had been diagnosed with brain metastases using computed tomography (CT) or magnetic resonance imaging (MRI); iii) The trials were anti-tumor agents plus radiotherapy (WBRT/SRS or in combination) which were considered as combination group vs. radiotherapy alone group; iv) Trials excluded patients with double or multiple primary cancer or presence of unstable systemic disease; v) The analyses included objective response rate (ORR), overall survival (OS), progression-free survival (PFS), time to central nervous system/neurological progression (CNS-TTP)/neurological PFS/progression-free survival of intracranial disease/local progression-free survival/interval to neurologic progression (all were assigned to CNS-TTP in the present study), severe adverse events (AEs; Grade $\geq 3$ ); vi) Response rate was determined using the Response Evaluation Criteria in Solid Tumors (RECIST 1.0 or 1.1 standards) or World Health Organization (WHO) criteria (11-13,15,17,18,21); vii) Adverse events were evaluated according to the National Cancer Institute Common Terminology Criteria for Adverse Events (CTCAE 2.0 or 3.0) or Radiation Therapy Oncology Group (RTOG) adverse events grading criteria $(3,10-12,14,15,17-21)$.

Data extraction and quality assessment. For each selected publication, the following information was extracted: First author, year of publication, country of original trial, type of trial, trial phase, number of patients, median ages, interventions and outcomes. To assess the quality and applicability of each previous study, checklists from The Cochrane Handbook for Systematic Reviews of intervention (version 5.1.0) were used, based on the following criteria: i) Random sequence generation; ii) Allocation concealment; iii) Blinding of participants and personnel; iv) Blinding of outcome assessment; v) Incomplete outcome data; vi) Selective reporting; vii) Other bias. Each trial for bias based on the criteria listed above was marked as low, high or unclear risk. The quality of the trails were defined as following: A rating, meeting all criteria of low risk; B rating, meeting one or more criteria of unclear risk without high risk; $\mathrm{C}$ rating, meeting one or more criteria of high risk.

Statistical analysis. Statistical analysis was performed using RevMan 5.3 software (Cochrane Collaboration's, which is a non-profit and non-governmental organization, Information Management System). Analysis of the data comprised of the pooled risk ratio (RR) for dichotomous endpoints (e.g., ORR, severe AEs), using the Mantel-Haenszel method (22). The events and total number of patients from the combination group and radiotherapy alone group in the trials for ORR and severe

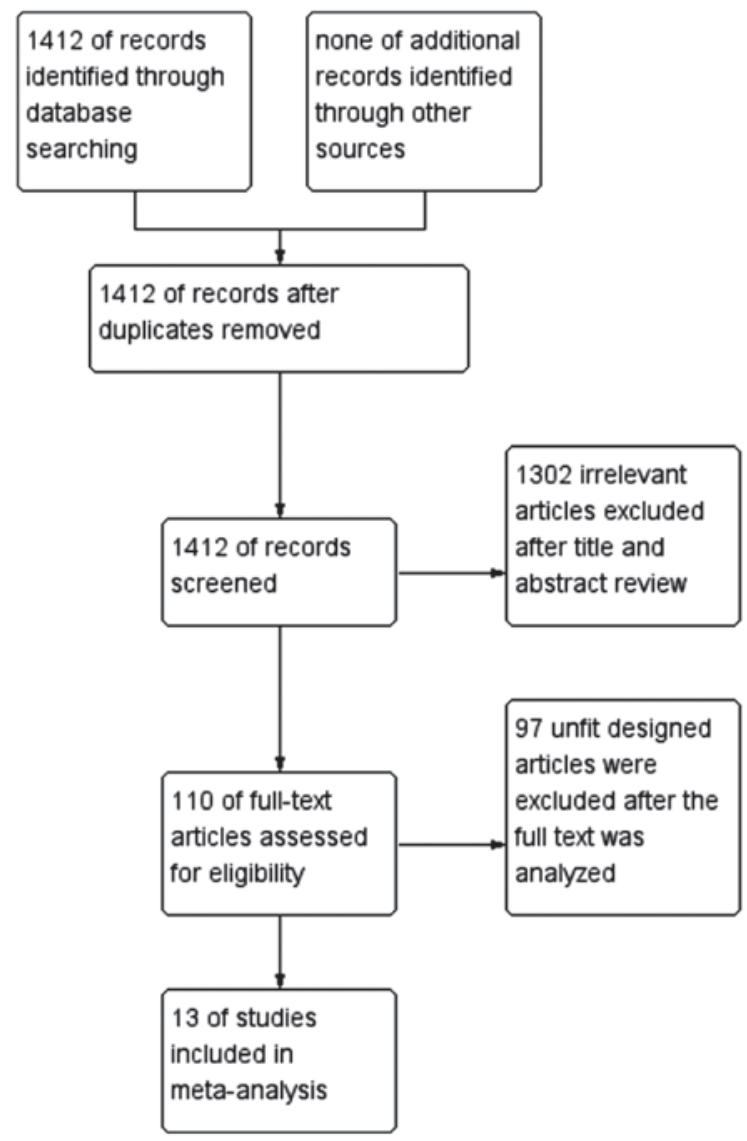

Figure 1. Flow chart highlighting the selection of included trials in the meta-analysis.

AEs were extracted from the trials (10-15, 17-21). OS, PFS and CNS-TTP were calculated using effect variables and expressed as the hazard ratio (HR). HRs with $95 \%$ confidence intervals (CIs) were extracted from trials or from the survival curves using the methods described by Tierney et al (23) for OS, PFS and CNS-TTP when HRs were unavailable. The 95\% CIs were calculated and presented in forest plots. Statistical heterogeneity of different trials was evaluated using the $\chi^{2}$ and $\mathrm{I}^{2}$ tests (24); no heterogeneity existed when $\mathrm{P}>0.1$ and $\mathrm{I}^{2}<50 \%$ and a fixed-effect model was applied to pool the study results. Significant heterogeneity was found if $\mathrm{P}<0.1$ or $\mathrm{I}^{2}>50 \%$, and a random-effects statistical model was used (25). The risk of publication bias was evaluated via visual appraisal of funnel plots.

\section{Results}

Study characteristics. A total of 1,412 previous studies met the selection criteria after searching the relevant databases. By verifying related terms in the titles and abstracts, 1,302 irrelevant articles and another 97 articles with an unfit design were excluded after the full text was analyzed. Finally, 13 clinical controlled trials $(3,10-21)$ were included in the present meta-analysis. A flowchart depicting inclusion is shown in Fig. 1.

In these 13 controlled trials, 1,783 patients with BMs were observed, including 853 patients with antitumor agents plus radiotherapy and 930 patients with radiotherapy alone. These results are summarized in Table I. Among these 13 trials, 5 were phase III clinical trials $(3,10,11,20,21), 6$ phase II 


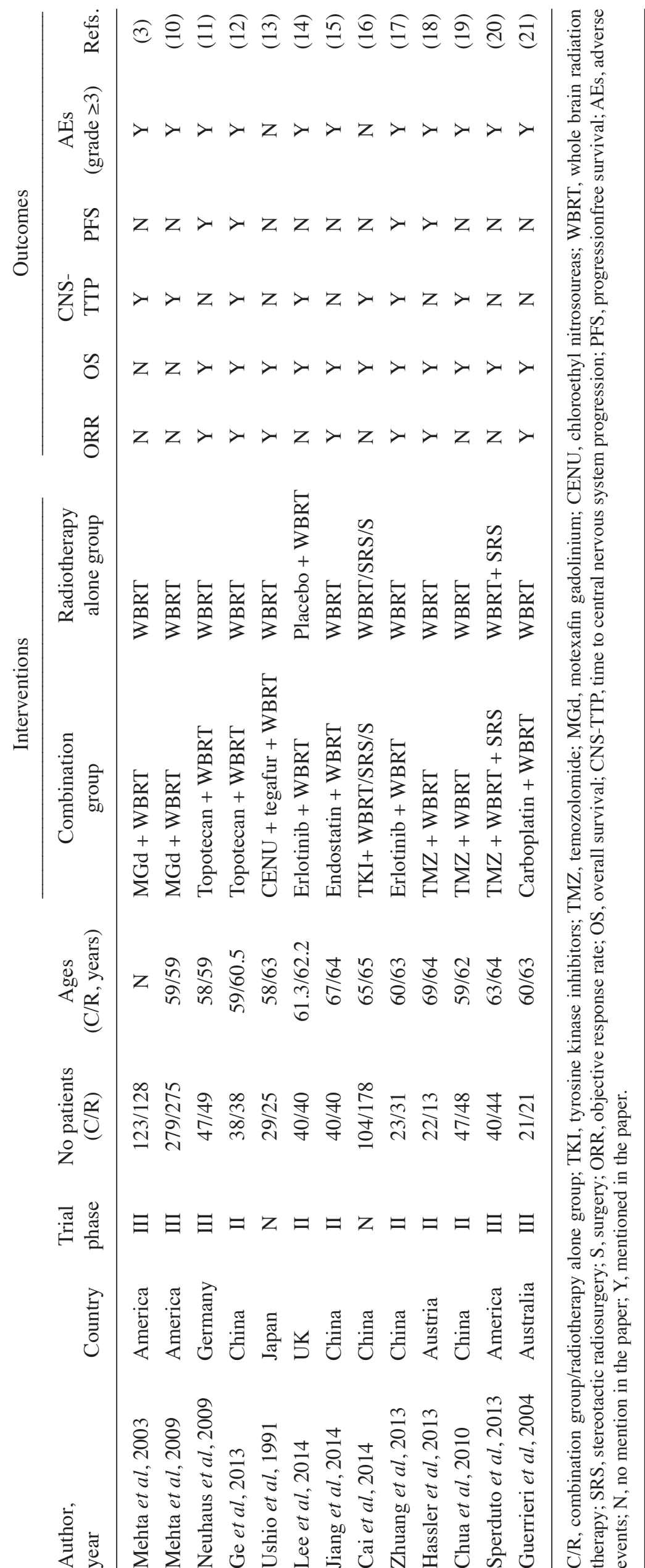




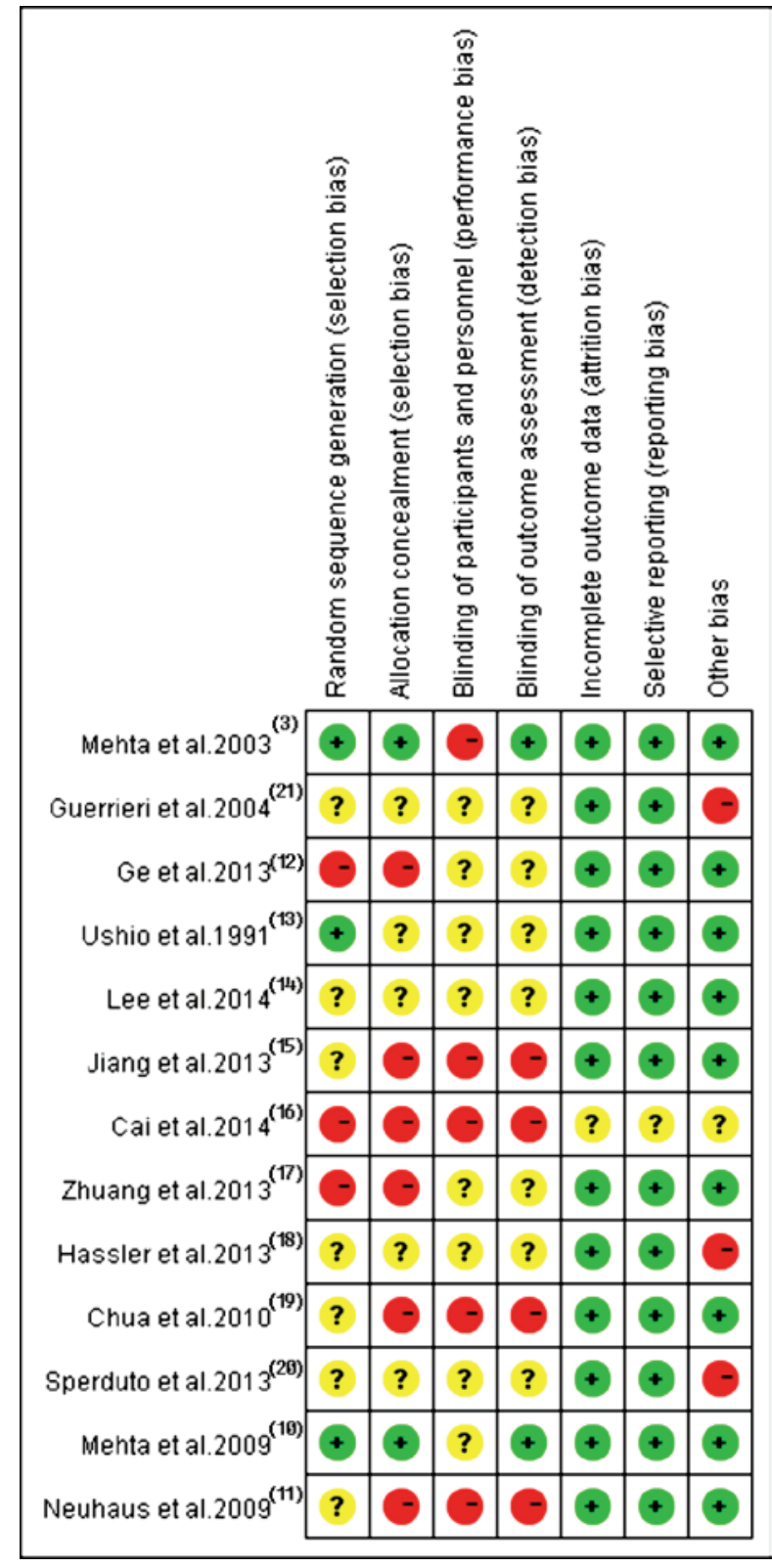

Figure 2. Bias risk and quality assessment of included trials.

trials $(12,14,15,17-19)$ and 2 studies failed to mention a trial phase $(13,16)$. Of these trails, 11 involved an antitumor agents plus WBRT, compared with WBRT alone $(3,10-15,17-19,21)$, and the others included antitumor agents combined with WBRT plus SRS, compared with WBRT plus SRS $(16,20)$. Outcomes included ORR, OS, PFS, CNS-TTP and severe AEs.

Data for all characteristics are summarized in Table II. Gender, Karnofsky performance score, number of BMs, extracranial metastases, histology, epidermal growth factor receptor mutation status and recursive partitioning analysis were available for $11,4,3,8,7,2$ and 5 of the 13 trials, respectively.

Methodological quality. In accordance with the recommendations of the Cochrane Handbook for Systematic Reviews, the present study assessed the eligible trials using the seven aspects mentioned above. Among these 13 recruited trials, ten $(3,10-11,13-15,18-21)$ referred to the use of random allocation, three discussed the methods $(3,10,13)$, two $(3,10)$
Table II. Patient characteristics.

\begin{tabular}{|c|c|c|}
\hline Characteristics & $\begin{array}{c}\text { Cgroup }(\%) \\
n=853\end{array}$ & $\begin{array}{c}\text { Rgroup }(\%) \\
n=930\end{array}$ \\
\hline \multicolumn{3}{|l|}{ Gender } \\
\hline Male & $414(49)$ & $454(49)$ \\
\hline Female & $276(32)$ & $304(33)$ \\
\hline Unknown & $163(19)$ & $172(18)$ \\
\hline \multicolumn{3}{|l|}{ KPS } \\
\hline$\geq 70$ & $389(46)$ & $394(42)$ \\
\hline$<70$ & $0(0)$ & $0(0)$ \\
\hline Unknown & $464(54)$ & $536(58)$ \\
\hline \multicolumn{3}{|l|}{ No. of BMs } \\
\hline$\leq 3$ & $82(10)$ & $87(9)$ \\
\hline$>3$ & $36(4)$ & $35(4)$ \\
\hline Unknown & $735(86)$ & $808(87)$ \\
\hline \multicolumn{3}{|c|}{ Extracranial metastases } \\
\hline Yes & $331(39)$ & $393(42)$ \\
\hline No & $287(34)$ & $310(33)$ \\
\hline Unknown & $235(27)$ & $227(25)$ \\
\hline \multicolumn{3}{|l|}{ Histology } \\
\hline Adenocarcinoma & $348(41)$ & $403(43)$ \\
\hline Squamous & $64(7)$ & $72(8)$ \\
\hline Other & $92(11)$ & $88(9)$ \\
\hline Unknown & $349(41)$ & $367(40)$ \\
\hline \multicolumn{3}{|l|}{ EGFR mutation } \\
\hline Positive & $40(5)$ & $26(3)$ \\
\hline Negative & $33(4)$ & $33(3)$ \\
\hline Unknown & $780(91)$ & $871(94)$ \\
\hline \multicolumn{3}{|l|}{ RPA } \\
\hline I & $57(7)$ & $55(6)$ \\
\hline II & $347(41)$ & 348 (37) \\
\hline Unknown & $449(52)$ & $527(57)$ \\
\hline
\end{tabular}

KPS, Karnofsky performance score; BM, brain metastases; EGFR, epidermal growth factor receptor; RPA, recursive partitioning analysis; Cgroup, combination group; Rgroup, radiotherapy alone group.

performed or reported their blinding methods and two $(18,19)$ reported their allocation concealment. All trials applied the intent-to-treat analysis and underwent quality assessment. Eventually, three $(10,13,14)$ received B quality scores and $10(3,11,12,15-21)$ received C quality scores, as shown in Fig. 2.

Local response rate. A total of seven trials $(11-13,15,17,18,21)$ testing response rate of treatment using antitumor agents plus radiotherapy compared with radiotherapy alone were identified. A fixed-effect model was utilized for the meta-analysis since heterogeneity did not exist $\left(\mathrm{P}=0.21 ; \mathrm{I}^{2}=28 \%\right)$. Notably, pooled data from the study results revealed a significant difference in terms of ORR between the groups of patients who were treated with antitumor agents plus radiotherapy and those who had received radiotherapy alone (RR, 1.38; 95\% CI, 1.19-1.60; P<0.0001) (Fig. 3). Subgroup analysis of 


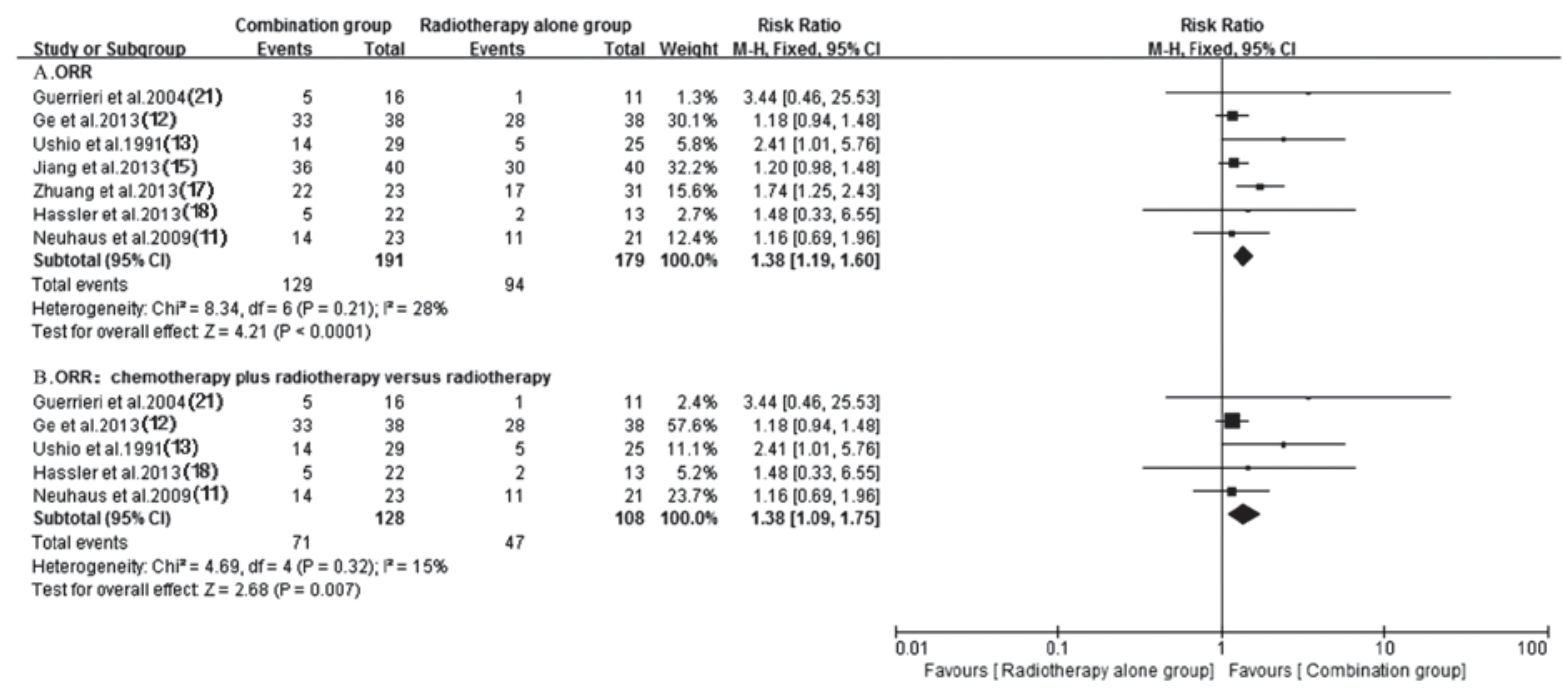

Figure 3. Objective response rate. (A) ORR of the trials. (B) Subgroup analysis of ORR for chemotherapy plus radiotherapy vs. radiotherapy alone. ORR, objective response rate; $\mathrm{CI}$, confidence interval.

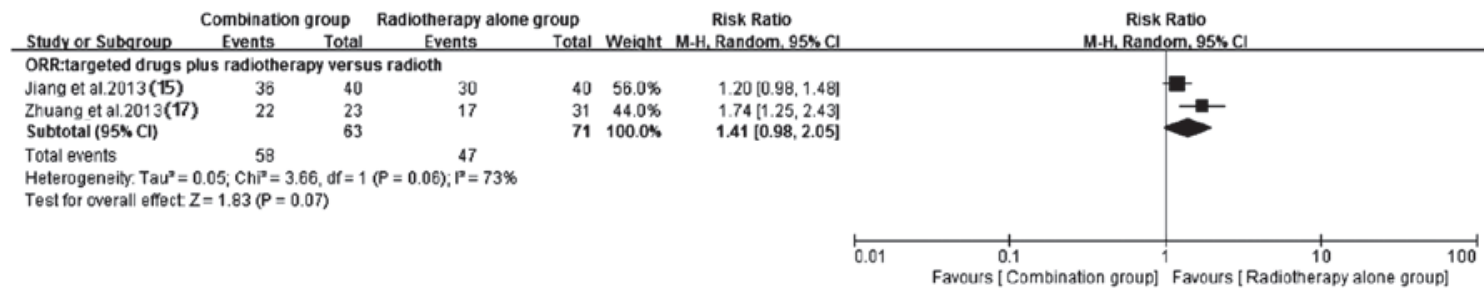

Figure 4. ORR for targeted drugs plus radiotherapy vs. radiotherapy alone. ORR, objective response rate; CI, confidence interval.

radiochemotherapy vs. radiotherapy alone demonstrated a significant ORR benefit for the radiochemotherapy arm (RR, 1.38; 95\% CI, 1.09-1.75; P=0.007) (Fig. 3). By contrast, a higher ORR $(\mathrm{P}=0.07)$ trend favoring targeted drugs plus radiotherapy group was observed $(15,17)$ despite the existence of heterogeneity ( $\left.\mathrm{P}=0.06 ; \mathrm{I}^{2}=73 \%\right)$ (Fig. 4).

Time to central nervous system progression. A total of seven trials $(3,10,12,14,16,17,19)$ reported time to central nervous system progression (CNS-TTP) in both groups. A random-effects model was applied based on the heterogeneity values $\left(\mathrm{P}=0.04, \mathrm{I}^{2}=54 \%\right)$. The outcome suggested that compared with radiotherapy alone, antitumor agents plus radiotherapy possessed a superior CNS-TTP for patients (HR, 0.71; 95\% CI, 0.57-0.90; $\mathrm{P}=0.004$ ) (Fig. 5). The subgroup analysis obtained a similar superior CNS-TTP in the tyrosine kinase inhibitor (TKI) plus radiotherapy group, compared with the radiotherapy alone group (HR, 0.58; $95 \%$ CI, 0.35-0.97; $\mathrm{P}=0.04$ ), although heterogeneity existed among them ( $\left.\mathrm{P}=0.03, \mathrm{I}^{2}=71 \%\right)$ (Fig. 5). Additionally, the prolonged CNS-TTP also appeared in the chemotherapy plus radiotherapy group (HR, $0.80 ; 95 \% \mathrm{CI}, 0.67-0.96 ; \mathrm{P}=0.02)$ without heterogeneity $\left(\mathrm{P}=0.76, \mathrm{I}^{2}=0 \%\right)$. Details of this pooled analysis are shown in Fig. 6.

Survival. A total of 11 trials (11-21) reported OS in both groups. Owing to the heterogeneity values $\left(\mathrm{P}=0.0002, \mathrm{I}^{2}=70 \%\right)$, a random-effects model was employed to analyze OS and no significantly longer OS was observed in the antitumor agents plus radiotherapy group compared with that in radiotherapy alone group (HR, 0.80; 95\% CI, 0.61-1.05; P=0.11) (Fig. 7). The funnel plot indicated no significant publication bias for OS (Fig. 8). Additionally, no prolonged OS was observed in the chemotherapy plus radiotherapy group compared with the radiotherapy alone group (HR, 0.96; 95\% CI, 0.79-1.17; $\mathrm{P}=0.68$ ) (Fig. 9). Notably, the OS of the targeted agents plus radiotherapy was significantly superior to radiotherapy alone (HR, 0.58; 95\% CI, 0.37-0.90; $\mathrm{P}=0.01$ ) with an important heterogeneity $\left(\mathrm{P}=0.02, \mathrm{I}^{2}=69 \%\right)$ (Fig. 7). A total of four trials $(11,12,17,18)$ reporting PFS were analyzed applying a fixed-effect model based on the heterogeneity values $(\mathrm{P}=0.52$, $\mathrm{I}^{2}=0 \%$ ) and revealed that, compared with radiotherapy alone, antitumor agents plus radiotherapy significantly prolonged PFS (HR, 0.60; 95\% CI, 0.44-0.83; P=0.002) (Fig. 10).

Adverse events. Of the included trials, eight (10-12,14,17-20) with sufficient data of treatment-related toxicity and severe AEs grading were applied to analyze AEs. A random-effects model was used to analyze overall severe AEs based on the heterogeneity values $\left(\mathrm{P}<0.0001, \mathrm{I}^{2}=81 \%\right)$. The results indicated that antitumor agents plus radiotherapy elevated the incidence of overall severe AEs (RR, 2.57; 95\% CI, 1.24-5.35; $\mathrm{P}=0.01$ ) (Fig. 11). Consequently, the present study performed a subgroup analysis for the severe AEs (Figs. 12 and 13). Hematotoxicity was the most common AE in the antitumor agents plus radiotherapy group. A notably higher incidence 
Hazard Ratio

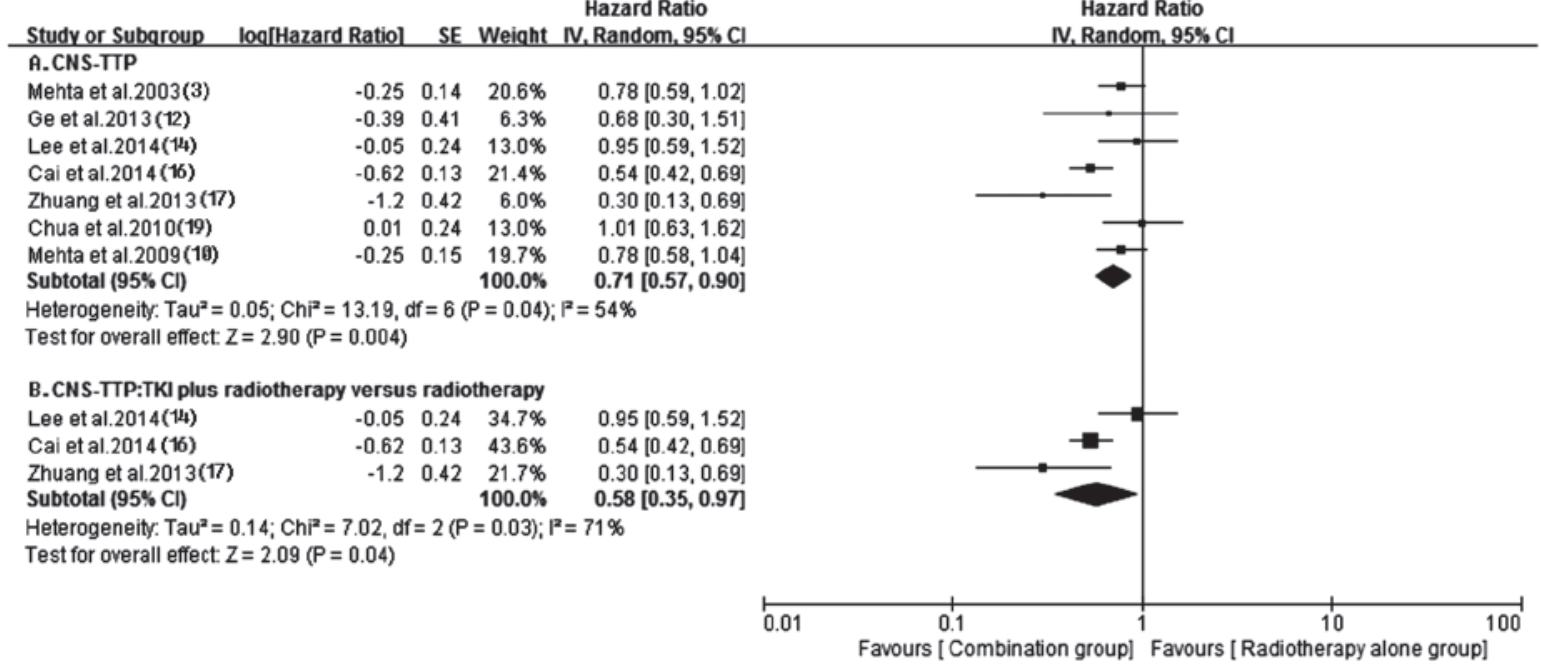

Figure 5. Time to central nervous system progression. (A) CNS-TTP of the trials. (B) Subgroup analysis of CNS-TTP for TKI plus radiotherapy vs. radiotherapy alone. CNS-TTP, time to central nervous system progression; TKI, tyrosine kinase inhibitors; CI, confidence interval.

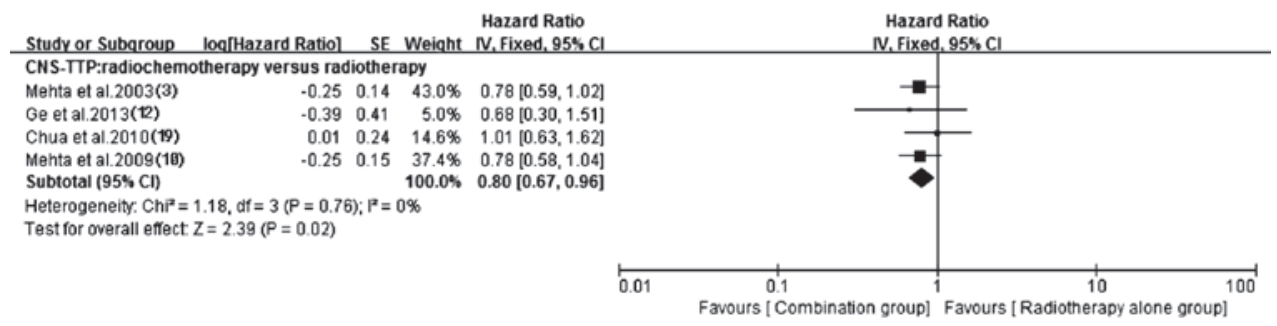

Figure 6. CNS-TTP for radiochemotherapy vs. radiotherapy alone. CNS-TTP, time to central nervous system progression; CI, confidence interval.

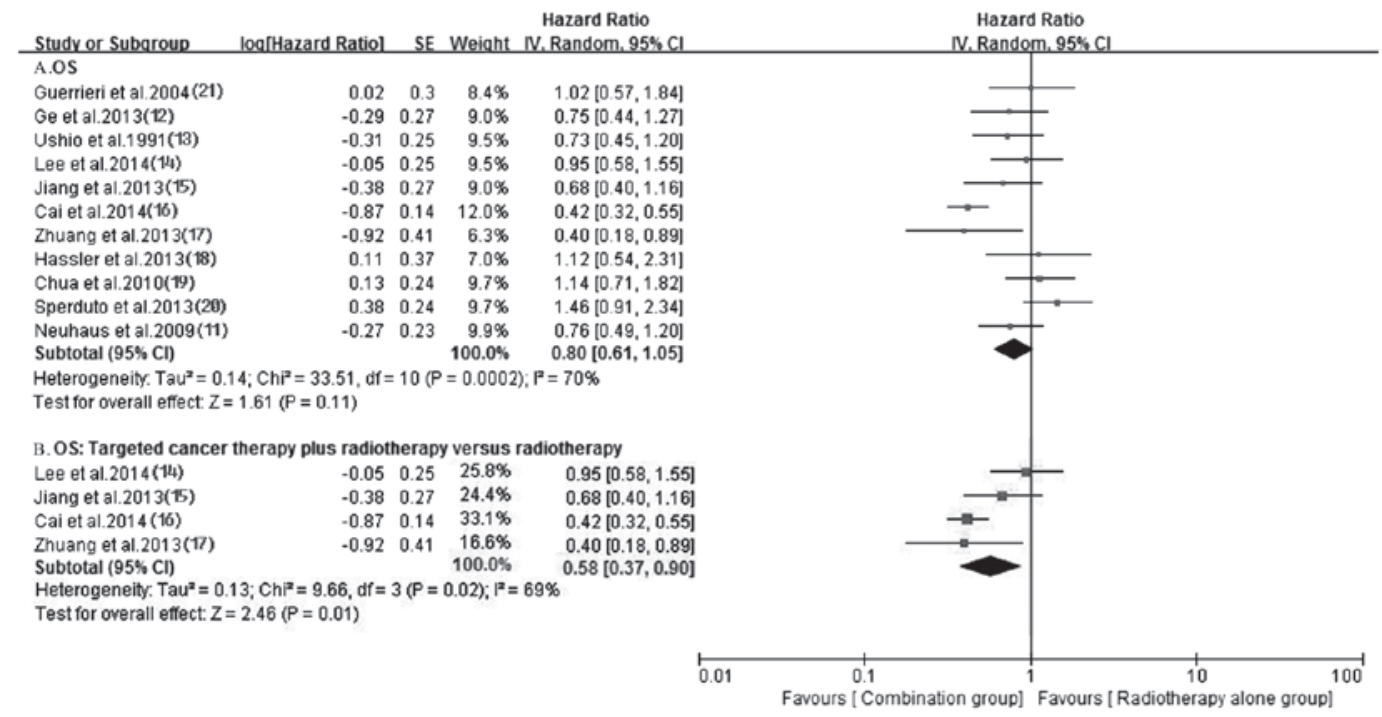

Figure 7. Overall survival. (A) OS of the trials. (B) Subgroup analysis of OS for targeted cancer therapy plus radiotherapy vs. radiotherapy alone. OS, overall survival; $\mathrm{CI}$, confidence interval.

of grade III-IV leukopenia (RR, 7.01; 95\% CI, 1.37-35.75; $\mathrm{P}=0.02)$ and thrombocytopenia (RR, 9.86; 95\% CI, 1.97-49.37; $\mathrm{P}=0.005)$ was observed in the antitumor agents plus radiotherapy group. However, the most common non-hematological AEs, which were largely mild and tolerable without significant difference between antitumor agents plus radiotherapy and radiotherapy alone, including fatigue/asthenia $(\mathrm{RR}, 0.82 ; 95 \%$ CI, 0.33-2.06; $\mathrm{P}=0.67$ ), dyspnea (RR, 1.65; 95\% CI, 0.32-8.63; $\mathrm{P}=0.55)$, pain ( $\mathrm{RR}, 1.28 ; 95 \% \mathrm{CI}, 0.27-6.14 ; \mathrm{P}=0.76)$, myopathy (RR, 0.72; 95\% CI, 0.14-3.67; P=0.70), nausea/vomiting ( $R R$, 1.61; 95\% CI, 0.73-3.54; $\mathrm{P}=0.23)$ and infection $(\mathrm{RR}, 2.19$; 95\% CI, 1.00-4.78; $\mathrm{P}=0.05$ ) (Fig. 13). Additionally, no severe 


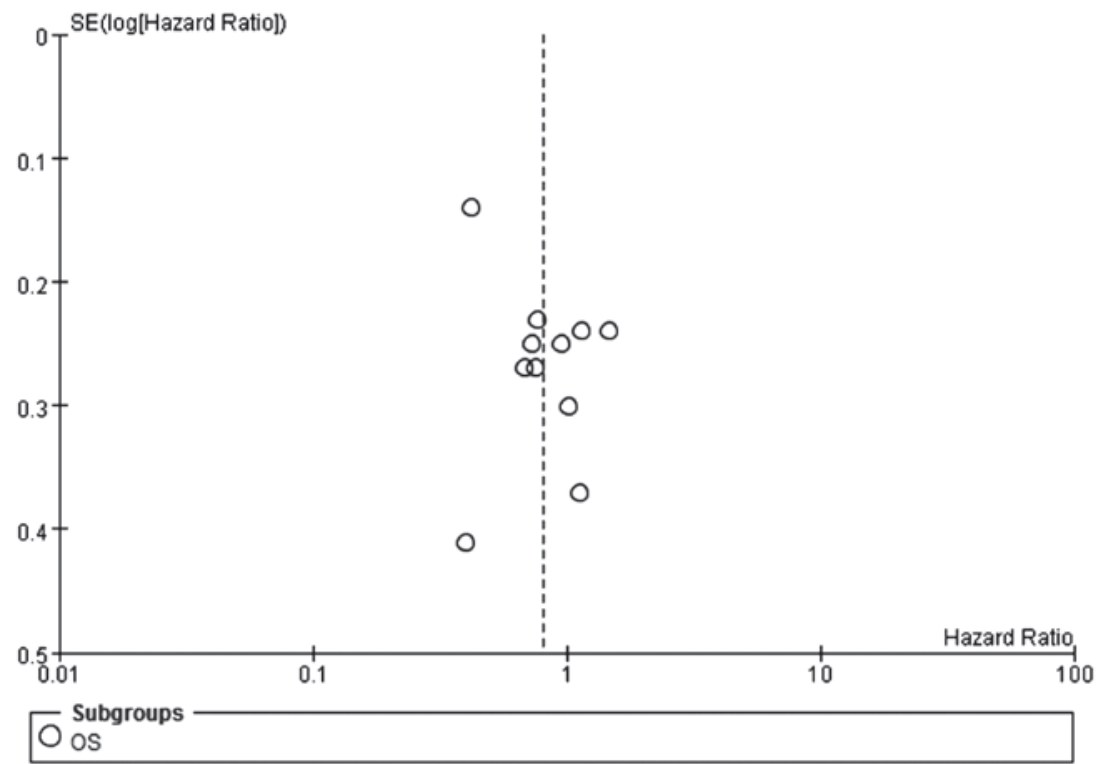

Figure 8. Funnel plot of OS for included trials. OS, overall survival.

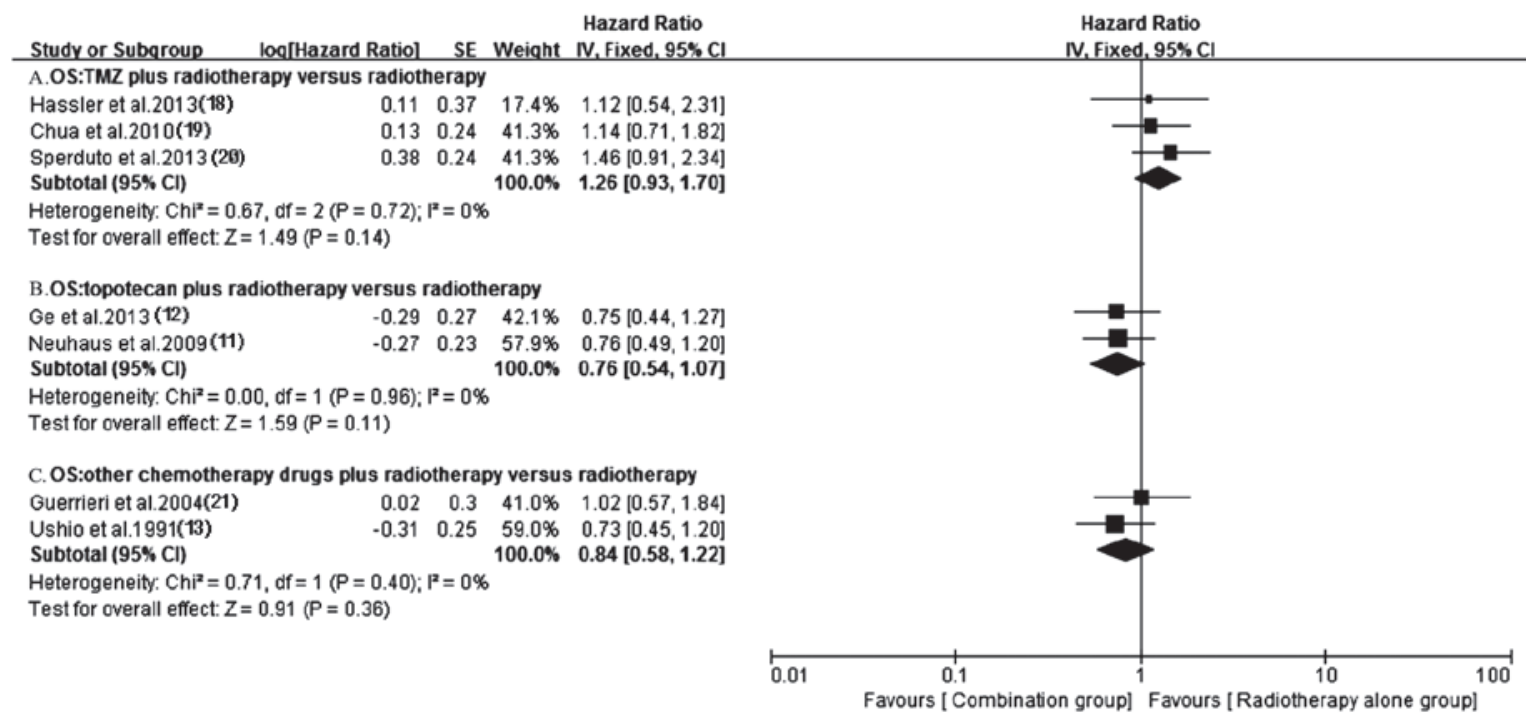

Figure 9. Subgroup analysis of OS for radiochemotherapy vs. radiotherapy alone. OS, overall survival; TMZ, temozolomide; CI, confidence interval.

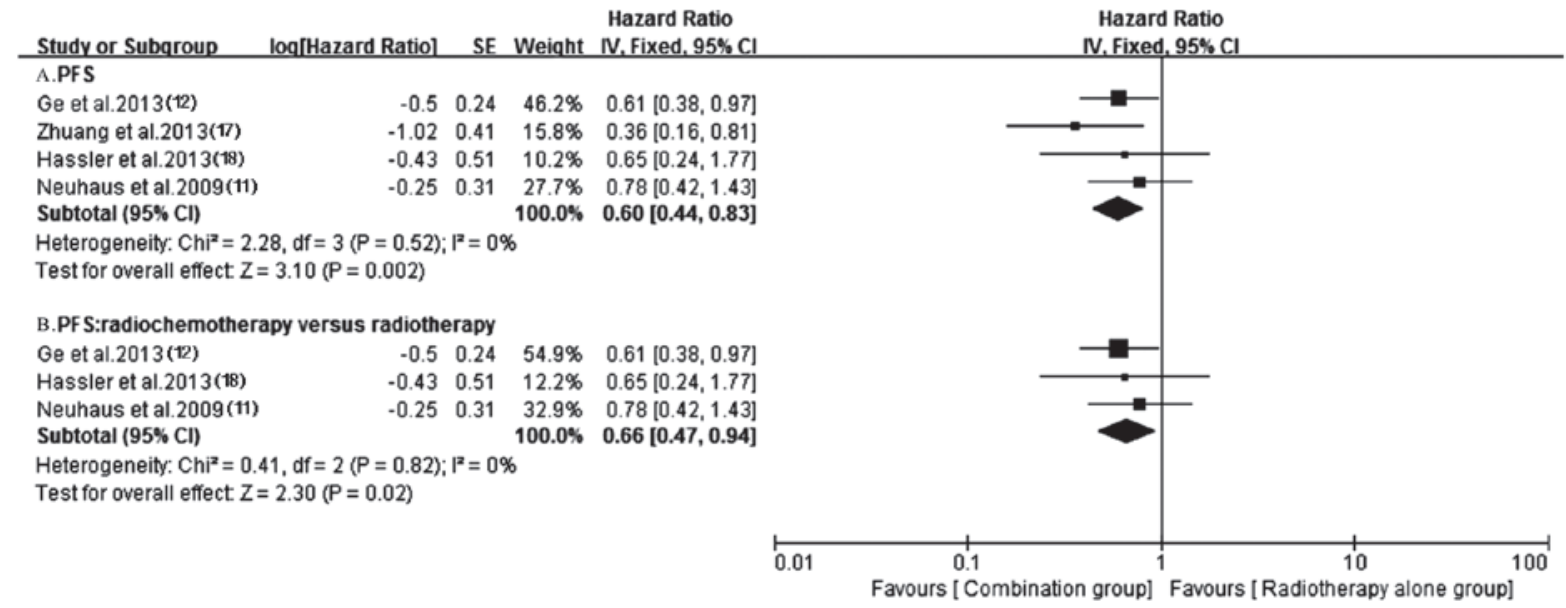

Figure 10. Progression-free survival. (A) PFS of the trials. (B) Subgroup analysis of PFS for radiochemotherapy vs. radiotherapy alone. PFS, progression-free survival; $\mathrm{CI}$, confidence interval. 


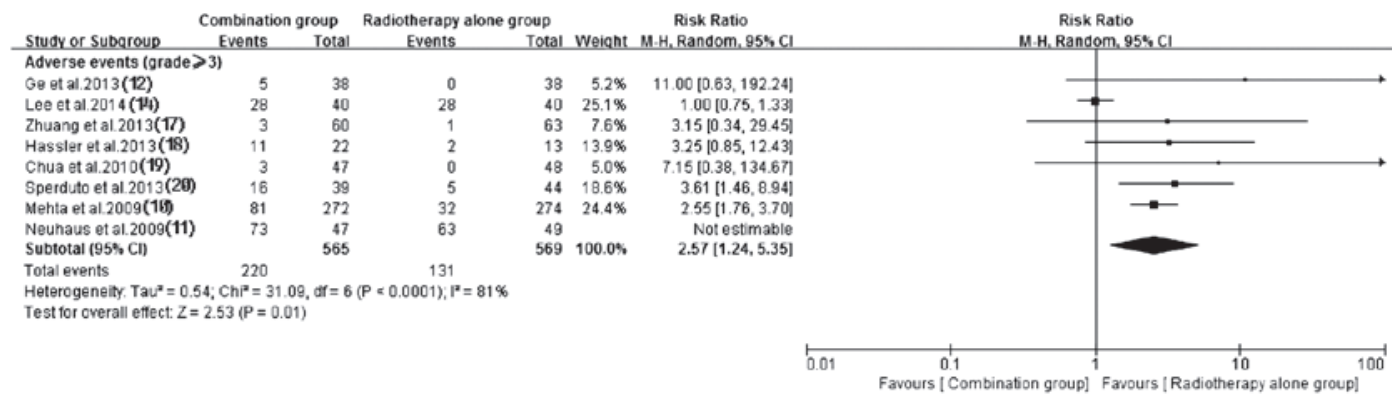

Figure 11. Overall severe AEs of the trials. AEs, adverse events; CI, confidence interval.

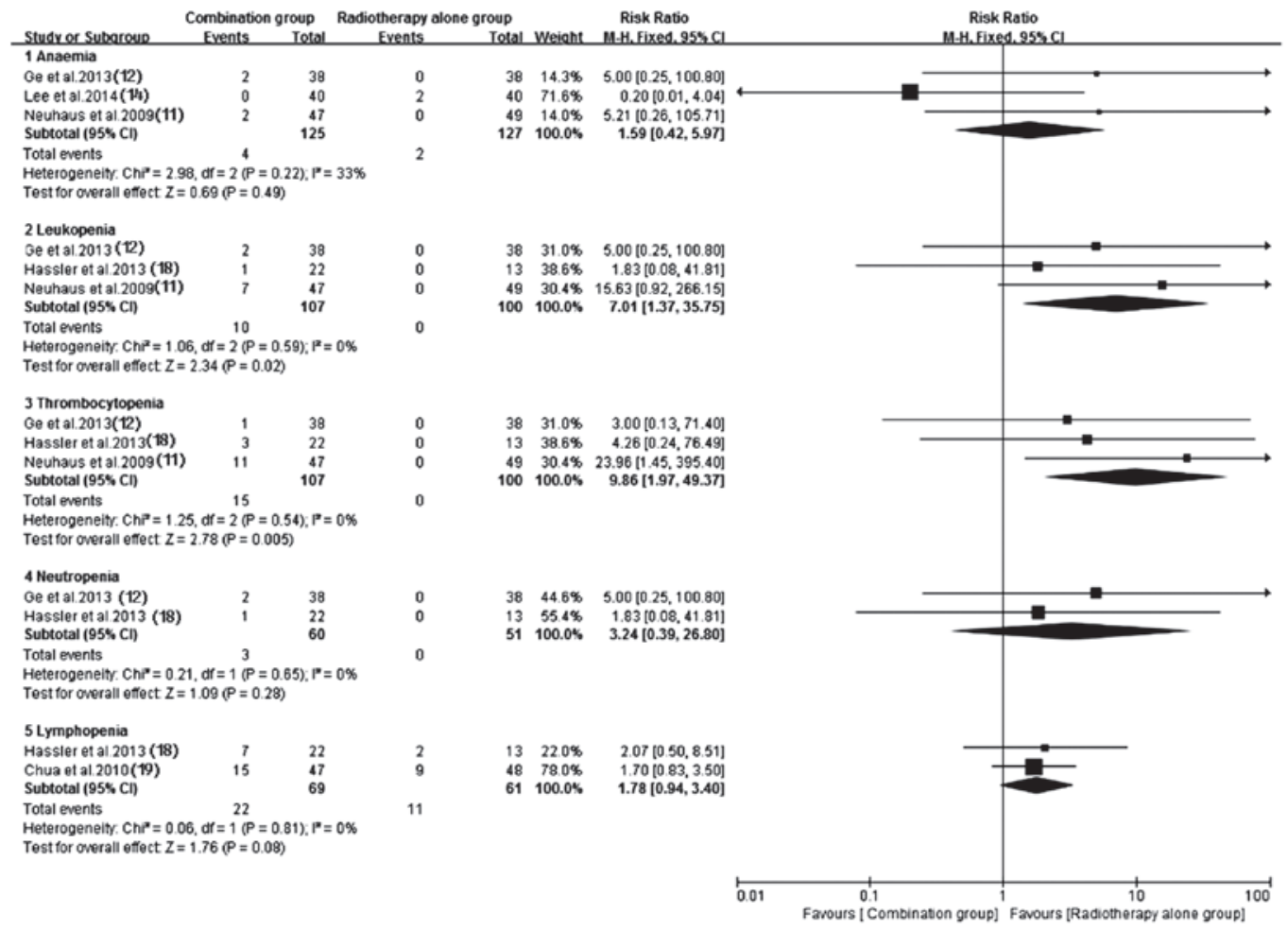

Figure 12. Severe hematotoxicity of the trials. CI, confidence interval.

hematotoxicity was observed in both the targeted agents plus radiotherapy group and the radiotherapy alone group.

\section{Discussion}

Since radiation therapy only acquires limited local control of $\mathrm{BMs}$, it is reasonable to make an attempt to combine antitumor agents with radiotherapy to maximize efficacy. Theoretically, due to the effect of the blood-brain barrier(BBB), the majority of chemotherapeutic agents were unable to reach sufficient concentration in BMs lesions (26), and LC patients with BMs may not gain benefit from these agents. However, previous clinical studies demonstrated that temozolomide, tegafur, chloroethyl nitrosoureas (methyl-CCNU or ACNU) and topotecan were effective in dealing with BMs, which partly derived from the distinctive property of the drugs, including their high capacity of penetrating the BBB and unique antitumor mechanisms (27-33). These interesting findings have inspired oncologists to design modality of combining antitumor agents with radiotherapy.
The present study demonstrated that antitumor agents plus radiotherapy possessed a significant benefit in terms of ORR, CNS-TTP and PFS, which may have a potential application value for LC patients with BMs. In addition, subgroup analysis also revealed superior ORR and CNS-TTP in the chemoradiotherapy group to radiotherapy alone group. The clinical outcomes may be elaborated by the following mechanisms: i) Radiotherapy, immature tumor angiogenesis and edema may amplify the destruction of the $\mathrm{BBB}$ and result in increasing permeability of the BBB (34-36); ii) certain antitumor agents own radiosensitizing effects $(37,38)$; iii) the tumor growth may disrupt the BBB (39).

Furthermore, the present study demonstrated that targeted agents plus radiotherapy prolonged the OS without severe hematotoxicity. The mechanisms may be as follows: i) Smaller molecular targeted agents possess a high capacity of penetrating the BBB $(40,41)$; ii) targeted agents have synergistic effect with radiotherapy in managing BMs (42); iii) unlike chemotherapy agents, targeted agents own a high selectivity 


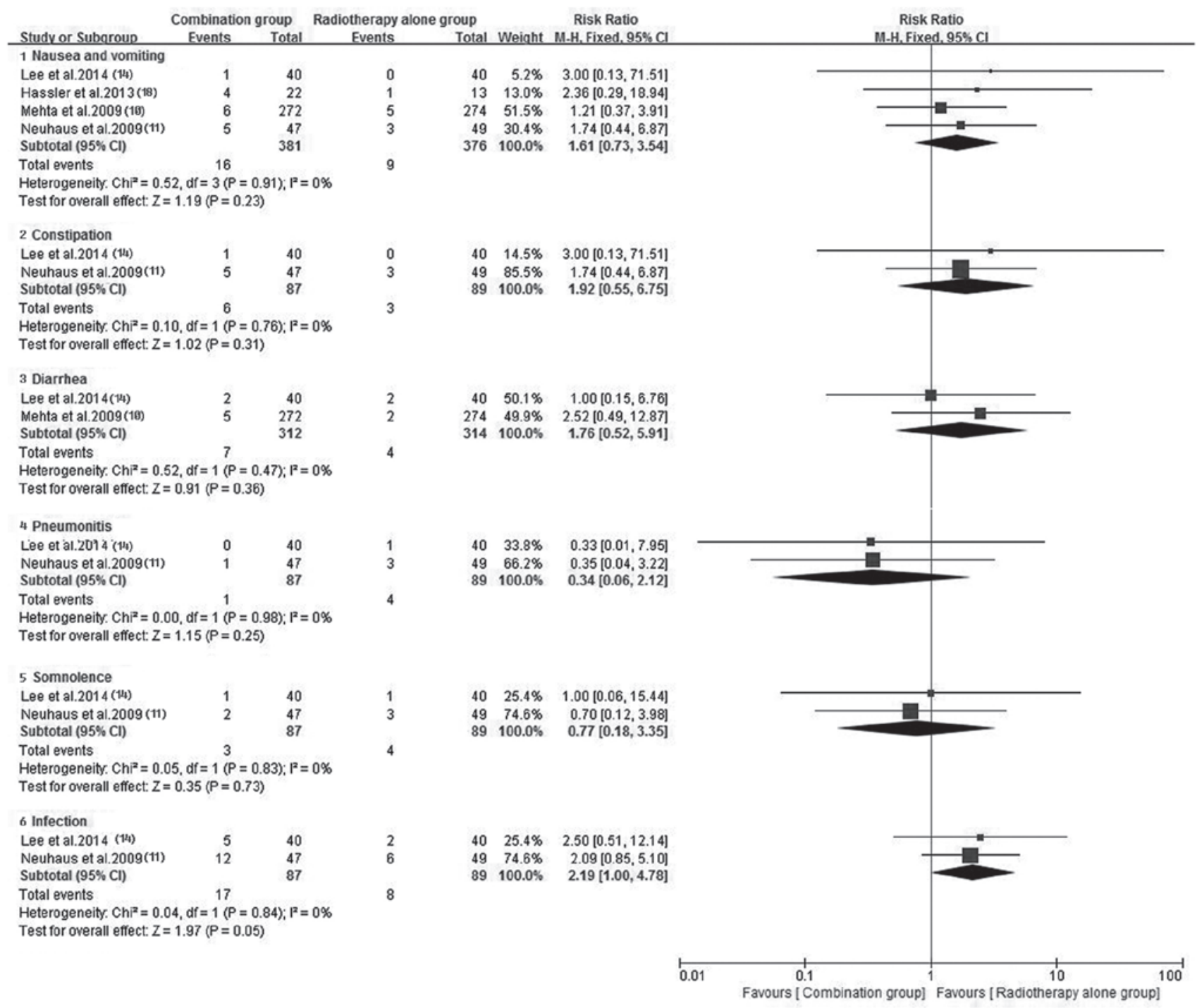

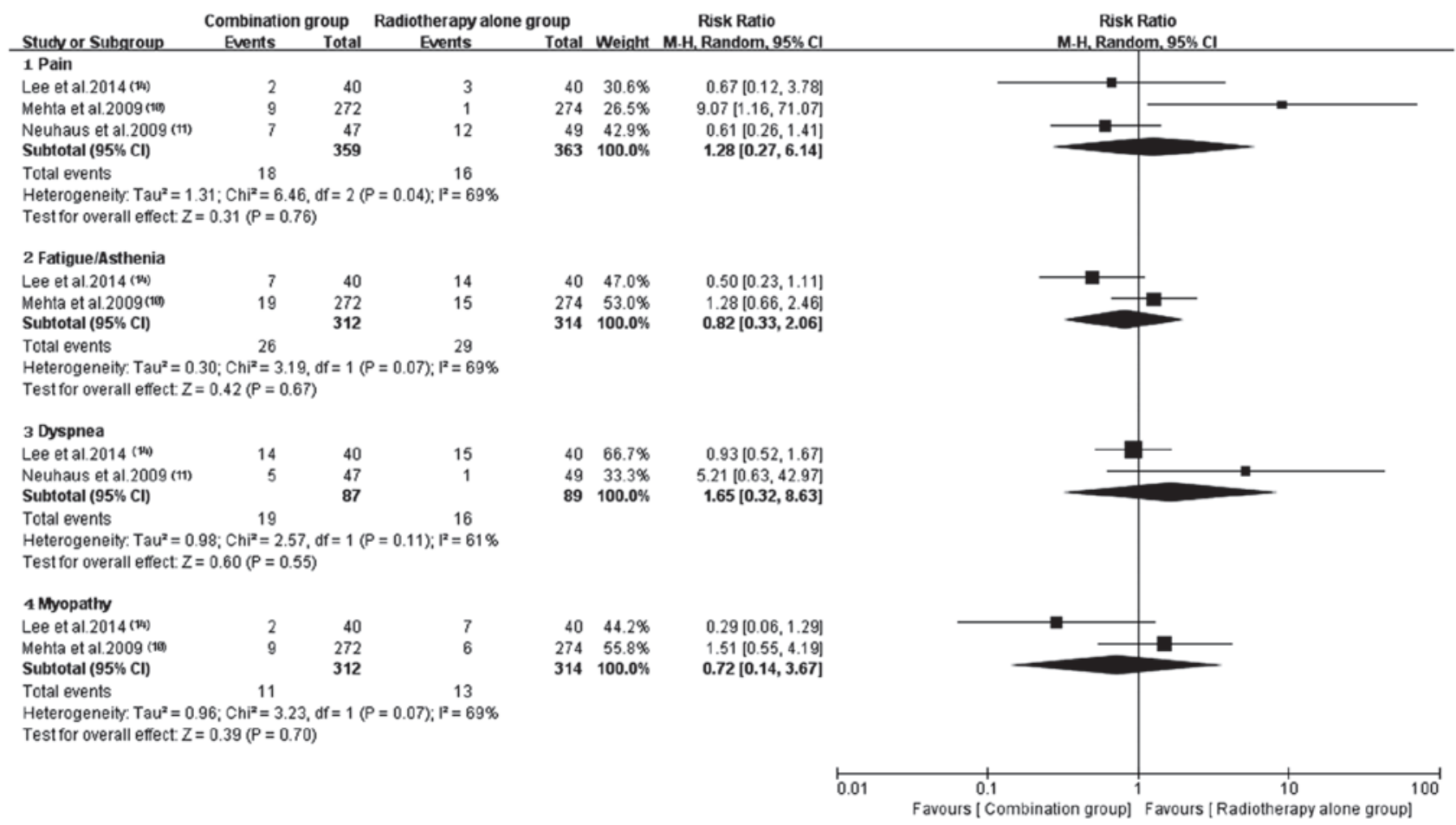

Figure 13. Severe non-hematotoxicity of the trials. CI, confidence interval. 
against cancer cells, which partly accounts for the mild and low toxicity of this regimen (43).

Undoubtedly, cytotoxic agents inhibited bone marrow cells, which accounted for the hematotoxicity observed in patients treated with chemotherapy, while EGFR-TKI therapy frequently resulted in mild and reversible acne rash and diarrhea (44). Compared with standard chemotherapy, the milder the toxicity profile was produced by EGFR-TKI, the less quality of life was intervened (45). Additionally, the higher risk of treatment interruption due to severe AEs in radiochemotherapy may partly explain its unfavorable OS.

In conclusion, the present study demonstrated that targeted agents plus radiotherapy yielded desirable effects with mild AEs. Therefore, it is advisable to combine targeted agents with radiotherapy to deal with inoperable BMs from LC. Secondary to best, chemoradiotherapy is an alternative option for patients without suitable molecular targets.

\section{References}

1. Soffietti R, Rudà R and Trevisan E: Brain metastases: Current management and new developments. Curr Opin Oncol 20: 676-684, 2008.

2. Delattre JY, Krol G, Thaler HT and Posner JB: Distribution of brain metastases. Arch Neurol 45: 741-744, 1988.

3. Mehta MP, Rodrigus P, Terhaard CH, Rao A, Suh J, Roa W, Souhami L, Bezjak A, Leibenhaut M, Komaki R, et al: Survival and neurologic outcomes in a randomized trial of motexafin gadolinium and whole-brain radiation therapy in brain metastases. J Clin Oncol 21: 2529-2536, 2003.

4. Sundstörm JT, Minn H, Lertola KK and Nordman E: Prognosis of patients treated for intracranial metastases with whole-brain irradiation. Ann Med 30: 296-299, 1998.

5. Patchell RA, Tibbs PA, Walsh JW, Dempsey RJ, Maruyama Y, Kryscio RJ, Markesbery WR, Macdonald JS and Young B: A randomized trial of surgery in the treatment of single metastases of the brain. N Engl J Med 322: 494-500, 1990.

6. Cho KH, Hall WA, Gerbi BJ, Higgins PD, Bohen M and Clark HB: Patient selection criteria for the treatment of brain metastases with stereotactic radiosurgery. J Neurooncol 40: 73-86, 1998.

7. Morris PG, Correa DD, Yahalom J, Raizer JJ, Schiff D, Grant B, Grimm S, Lai RK, Reiner AS, Panageas K, et al: Rituximab, methotrexate, procarbazine, and vincristine followed by consolidation reduced-dose whole-brain radiotherapy and cytarabine in newly diagnosed primary CNS lymphoma: Final results and long-term outcome. J Clin Oncol 31: 3971-3979, 2013.

8. Cortot $\mathrm{AB}$, Gerinière L, Robinet $\mathrm{G}$, Breton JL, Corre R, Falchero L, Berard H, Gimenez C, Chavaillon JM, Perol M, et al: Phase II trial of temozolomide and cisplatin followed by whole brain radiotherapy in non-small-cell lung cancer patients with brain metastases: A GLOT-GFPC study. Ann Oncol 17: 1412-1417, 2006.

9. Lukas RV, Nicholas MK, Villaflor V, Hoffman PC and Salgia R: Temozolomide and/or erlotinib in the treatment of lung cancer patients with progressive central nervous system metastases. J Neurol Res 2: 1-9, 2012.

10. Mehta MP, Shapiro WR, Phan SC, Gervais R, Carrie C, Chabot P, Patchell RA, Glantz MJ, Recht L, Langer C, et al: Motexafin gadolinium combined with prompt whole brain radiotherapy prolongs time to neurologic progression in non-small-cell lung cancer patients with brain metastases: Results of a phase III trial. Int J Radiat Oncol Biol Phys 73: 1069-1076, 2009.

11. Neuhaus T, Ko Y, Muller RP, Grabenbauer GG, Hedde JP, Schueller H, Kocher M, Stier S and Fietkau R: A phase III trial of topotecan and whole brain radiation therapy for patients with CNS-metastases due to lung cancer. Br J Cancer 100: 291-297, 2009.

12. Ge XH, Lin Q, Ren XC, Liu YE, Chen XJ, Wang DY, Wang YQ, Cao B, Li ZG and Liu ML: Phase II clinical trial of whole-brain irradiation plus three-dimensional conformal boost with concurrent topotecan for brain metastases from lung cancer. Radiat Oncol 8: 238, 2013.
13. Ushio Y, Arita N, Hayakawa T, Mogami H, Hasegawa H, Bitoh S, Oku Y, Ikeda H, Kanai N and Kanoh M: Chemotherapy of brain metastases from lung carcinoma: A controlled randomized study. Neurosurgery 28: 201-205, 1991.

14. Lee SM, Lewanski CR, Counsell N, Ottensmeier C, Bates A, Patel N, Wadsworth C, Ngai Y, Hackshaw A and Faivre-Finn C: Randomized trial of erlotinib plus whole-brain radiotherapy for NSCLC patients with multiple brain metastases. J Natl Cancer Inst 106: pii: dju151, 2014

15. Jiang X, Ding M, Qiao Y, Liu Y and Liu L: Recombinant human endostatin combined with radiotherapy in the treatment of brain metastases of non-small cell lung cancer. Clin Transl Oncol 16: 630-636, 2014

16. Cai L, Zhu JF, Zhang XW, Lin SX, Su XD, Lin P, Chen K and Zhang LJ: A comparative analysis of EGFR mutation status in association with the efficacy of TKI in combination with WBRT/SRS/surgery plus chemotherapy in brain metastasis from non-small cell lung cancer. J Neurooncol 120: 423-430, 2014.

17. Zhuang H, Yuan Z, Wang J, Zhao L, Pang Q and Wang P: Phase II study of whole brain radiotherapy with or without erlotinib in patients with multiple brain metastases from lung adenocarcinoma. Drug Des Devel Ther 7: 1179-1186, 2013.

18. Hassler MR, Pfeifer W, Knocke-Abulesz TH, Geissler K, Altorjai G, Dieckmann K and Marosi C: Temozolomide added to whole brain radiotherapy in patients with multiple brain metastases of non-small-cell lung cancer: A multicentric Austrian phase II study. Wien Klin Wochenschr 125: 481-486, 2013.

19. Chua D, Krzakowski M, Chouaid C, Pallotta MG, Martinez JI, Gottfried M, Curran W and Throuvalas N: Whole-brain radiation therapy plus concomitant temozolomide for the treatment of brain metastases from non-small-cell lung cancer: A randomized, open-label phase II study. Clin Lung Cancer 11: 176-181, 2010.

20. Sperduto PW, Wang M, Robins HI, Schell MC, Werner-Wasik M, Komaki R, Souhami L, Buyyounouski MK, Khuntia D, Demas W, et al: A phase 3 trial of whole brain radiation therapy and stereotactic radiosurgery alone versus WBRT and SRS with temozolomide or erlotinib for non-small cell lung cancer and 1 to 3 brain metastases: Radiation therapy oncology group 0320. Int J Radiat Oncol Biol Phys 85: 1312-1318, 2013.

21. Guerrieri M, Wong K, Ryan G, Millward M, Quong G and Ball DL: A randomized phase III study of palliative radiation with concomitant carboplatin for brain metastases from non-small cell carcinoma of the lung. Lung Cancer 46: 107-111, 2004.

22. Mantel N and Haenszel W: Statistical aspects of the analysis of data from retrospective studies of disease. J Natl Cancer Inst 22: 719-748, 1959.

23. Tierney JF, Stewart LA, Ghersi D, Burdett S and Sydes MR: Practical methods for incorporating summary time-to-event data into meta-analysis. Trials 8: 16, 2007.

24. Higgins JP, Thompson SG, Deeks JJ and Altman DG: Measuring inconsistency in meta-analyses. BMJ 327: 557-560, 2003.

25. Ford AC, Forman D, Hunt RH, Yuan Y and Moayyedi P: Helicobacter pylori eradication therapy to prevent gastric cancer in healthy asymptomatic infected individuals: Systematic review and meta-analysis of randomized controlled trials. BMJ 348: g3174, 2014.

26. Van Vulpen M, Kal HB, Taphoorn MJ and El Sharouni S: Changes in blood-brain barrier permeability induced by radiotherapy: Implications for timing of chemotherapy? (Review) Oncol Rep 9: 683-688, 2002

27. Middlemas DS, Stewart CF, Kirstein MN, Poquette C, Friedman HS, Houghton PJ and Brent TP: Biochemical correlates of temozolomide sensitivity in pediatric solid tumor xenograft models. Clin Cancer Res 6: 998-1007, 2000.

28. Raymond E, Izbicka E, Soda H, Gerson SL, Dugan M and Von Hoff DD: Activity of temozolomide against human tumor colony-forming units. Clin Cancer Res 3: 1769-1074, 1997.

29. Srivenugopal KS, Shou J, Mullapudi SR, Lang FF Jr, Rao JS and Ali-Osman F: Enforced expression of wild-type p53 curtails the transcription of the $\mathrm{O}(6)$-methylguanine-DNA methyltransferase gene in human tumor cells and enhances their sensitivity to alkylating agents. Clin Cancer Res 7: 1398-4009, 2001.

30. Kohno T, Shitara N, Takakura K and Fujita H: Role of FT-207 in the treatment of metastatic brain tumors. Cancer Chemother (Tokyo) 3: 729-734, 1976.

31. Ushio Y, Posner JB and ShapiroWR: Chemotherapy of experimental meningeal carcinomatosis. Cancer Res 37: 1232-1237, 1977. 
32. Sung C, Blaney SM, Cole DE, Balis FM and Dedrick RL: A pharmacokinetic model of topotecan clearance from plasma and cerebrospinal fluid. Cancer Res 54: 5118-5122, 1994

33. Baker SD, Heideman RL, Crom WR, Kuttesch JF, Gajjar A and Stewart CF: Cerebrospinal fluid pharmacokinetics and penetration of continuous infusion topotecan in children with central nervous system tumors. Cancer Chemother Pharmacol 37: 195-202, 1996

34. O'Connor MM and Mayberg MR: Effects of radiation on cerebral vasculature: A review. Neurosurgery 46:138-151, 2000.

35. Hutchinson F: Molecular biology of mutagenesis of mammalian cells by ionizing radiation. Semin Cancer Biol 4: 85-92, 1993.

36. Harms-Ringdahl M, Nicotera P and Radford IR: Radiation induced apoptosis. Mutat Res 366: 171-179, 1996.

37. Groen H, Sleijfer S, Meijer C, Kampinga HH, Konings AW, De Vries EG and Mulder NH: Carboplatin- and cisplatin-induced potentiation of moderate-dose radiation cytotoxicity in human lung cancer cell lines. Br J Cancer 72: 1406-1411, 1995.

38. Xu S, Zakian K, Thaler H, Matei C, Alfieri A, Chen Y and Koutcher JA: Effects of motexafin gadolinium on tumor metabolism and radiation sensitivity. Int $\mathbf{J}$ Radiat Oncol Biol Phys 49: 1381-1390, 2001

39. Grimm SA: Treatment of brain metastases: Chemotherapy. Curr Oncol Rep 14: 85-90, 2012

40. Weber B, Winterdahl M, Memon A, Sorensen BS, Keiding S, Sorensen L, Nexo E and Meldgaard P: Erlotinib accumulation in brain metastases from non-small cell lung cancer: Visualization by positron emission tomography in a patient harbouring a mutation in the epidermal growth factor receptor. J Thorac Oncol 6: $1287-1289,2011$
41. McKillop D, Hutchison M, Partridge EA, Bushby N, Cooper CM, Clarkson-Jones JA, Herron W and Swaisland HC: Metabolic disposition of Gefitinib, an epidermal growth factor receptor tyrosine kinase inhibitor, in rat, dog and man. Xenobiotica 34: 917-934, 2004.

42. Chinnaiyan P, Huang S, Vallabhaneni G, Armstrong E, Varambally S, Tomlins SA, Chinnaiyan AM and Harari PM: Mechanisms of enhanced radiation response following epidermal growth factor receptor signaling inhibition by erlotinib (Tarceva). Cancer Res 65: 3328-3335, 2005

43. Chen X, Pan Y, Zhang S, Chen D, Yang S, Li X and Ma S: Rechallenge with gefitinib following severe drug-induced hepatotoxicity in a patient with advanced non-small cell lung cancer: A case report and literature review. Oncol Lett 7: 878-880, 2014

44. Hirsh V: Managing treatment-related adverse events associated with egfr tyrosine kinase inhibitors in advanced non-small cell lung cancer. Curr Oncol 18: 126-138, 2011.

45. Fukuoka M, Wu YL, Thongprasert S, Sunpaweravong $P$, Leong SS, Sriuranpong V, Chao TY, Nakagawa K, Chu DT, Saijo N, et al: Biomarker analyses and final overall survival results from a phase III, randomized, open-label, first-line study of gefitinib versus carboplatin/paclitaxel in clinically selected patients with advanced non-small-cell lung cancer in Asia (IPASS). J Clin Oncol 29: 2866-2874, 2011. 